\title{
Peroxynitrite Inhibits Leukocyte-Endothelial Cell Interactions and Protects Against Ischemia-Reperfusion Injury in Rats
}

\author{
David J. Lefer, ${ }^{\star}$ Rosario Scalia, ${ }^{\ddagger}$ Barry Campbell, ${ }^{\ddagger}$ Tareck Nossuli, ${ }^{\ddagger}$ Reid Hayward, ${ }^{\ddagger}$ Michael Salamon, ${ }^{\ddagger}$ Jeremy Grayson, ${ }^{\ddagger}$ \\ and Allan M. Lefer ${ }^{\ddagger}$ \\ *Department of Medicine, Cardiology Section, SL-48, Tulane University School of Medicine, New Orleans, Louisiana 70112; \\ and ${ }^{\ddagger}$ Department of Physiology, Jefferson Medical College, Thomas Jefferson University, Philadelphia, Pennsylvania 19107-6799
}

\begin{abstract}
Peroxynitrite $\left(\mathrm{ONOO}^{-}\right)$anion, formed by the interaction of superoxide with nitric oxide (NO), has previously been implicated as a cytotoxic agent. However, the effects of this free radical species on neutrophil (PMN)-endothelial cell interactions is largely unknown. We investigated the direct actions of $\mathrm{ONOO}^{-}$on PMN adhesion to endothelial cells in vitro and in vivo, as well as the effects of $\mathrm{ONOO}^{-}$on $\mathrm{PMN}-$ mediated myocardial ischemia-reperfusion injury. In vitro, peroxynitrite (100-1,000 $\mathrm{nM}$ ) inhibited the adhesion of rat PMNs to the endothelium of isolated thrombin- or $\mathrm{H}_{2} \mathrm{O}_{2}$ stimulated rat mesenteric artery $(P<0.01$ vs. thrombin or $\mathrm{H}_{2} \mathrm{O}_{2}$ alone). In vivo, in the rat mesentery, thrombin $(0.5 \mathrm{U} /$ ml) or $N^{\mathrm{G}}$-nitro-L-arginine-methyl ester $(50 \mu \mathrm{M})$ significantly increased venular leukocyte rolling and adherence, which were also significantly $(P<0.01)$ attenuated by $\mathrm{ONOO}^{-}(800 \mathrm{nM})$ accompanied by reduced P-selectin expression on the endothelial cell surface. Isolated perfused rat hearts were subjected to global ischemia and reperfusion with rat PMNs $\left(10^{8}\right.$ cells), which resulted in profound cardiac depression (i.e., a marked reduction in left ventricular developed pressure and maximal rate of development of left ventricular pressure). Infusion of $\mathrm{ONOO}^{-}$reversed the myocardial contractile dysfunction of ischemic-reperfused rat hearts to near baseline levels, and markedly attenuated the accumulation of PMNs in the postischemic heart. The present study provides strong evidence that nanomolar concentrations of $\mathrm{ONOO}^{-}$both inhibit leukocyte-endothelial cell interactions and exert cytoprotective effects in myocardial ischemia-reperfusion injury. Furthermore, our results suggest that the inhibition of $\mathrm{P}$-selectin expression by peroxynitrite is a key mechanism of the modulatory actions of $\mathrm{ONOO}^{-}$on leukocyte-endothelial cell interactions. (J. Clin. Invest. 1997. 99:684-691.) Key words: neutrophil adherence • P-selectin • myeloperoxidase activity • nitric oxide $\bullet$ cardiac contractility
\end{abstract}

\footnotetext{
Address correspondence to Allan M. Lefer, Department of Physiology, Jefferson Medical College, Thomas Jefferson University, 1020 Locust Street, Philadelphia, PA 19107-6799. Phone: 215-503-7760; FAX: 215-503-2073; E-mail: lefer1@jeflin.tju.edu

Received for publication 23 September 1996 and accepted in revised form 3 December 1996.
}

J. Clin. Invest.

(C) The American Society for Clinical Investigation, Inc. 0021-9738/97/02/0684/08 \$2.00

Volume 99, Number 4, February 1997, 684-691

\section{Introduction}

In recent years, considerable research has focused on the physiological, biochemical, and molecular actions of nitric oxide (NO) in normal physiological processes as well as during pathological conditions. NO, at low nanomolar concentrations, has been shown to modulate a number of physiological processes relating to vascular reactivity (1), platelet function (2), leukocyte-endothelial cell interactions in the microcirculation (3-5), and vascular permeability (6). In this regard, these concentrations of NO have been shown to be cytoprotective in a number of experimental vascular disease states including ischemia-reperfusion injury $(7,8)$, respiratory distress syndromes (9), intimal hyperplasia associated with vessel injury (10), atherosclerosis (11), and vascular thrombosis (12). However, other experimental studies have suggested that micromolar concentrations of NO are cytotoxic and contribute to cell injury in a variety of disease states including disorders of the lung (13), endotoxic and hypovolemic shock states $(14,15)$, ischemia-reperfusion injury (16), and anoxia-reoxygenation injury (17). Moreover, it has been suggested that the purported toxic effects of $\mathrm{NO}$ are a result of the formation of a free radical species formed via the interaction between NO and superoxide, which has been reported to be peroxynitrite $\left(\mathrm{ONOO}^{-}\right)$(18).

Beckman et al. (19) first reported that $\mathrm{NO}$ and superoxide could combine to form $\mathrm{ONOO}^{-}$and that the resulting acid, peroxynitrous acid, was a major source of the biologically active hydroxyl radical. Furthermore, it has been proposed (1922) that the hydroxyl radical formed from peroxynitrite is highly cytotoxic and can result in profound cellular injury and cell death. Szabo et al. (22) reported that peroxynitrite is formed during endotoxemia and contributes to the cellular injury associated with both endotoxic and hemorrhagic shock. Moreover, this injury could be avoided by inhibition of NO production (22). Ischiropoulos and Al-Mehdi (23) have recently reported that peroxynitrite can cause protein fragmentation via oxidative stress, and that peroxynitrite-mediated inactivation of important regulatory proteins may contribute to its toxicity. In this regard, peroxynitrite is thought to be involved in ischemic rat lung injury (20) and in the lung injury associated with endotoxemia (21). Moreover, Schulz and Wambolt (16) have reported that some free radical species, possibly peroxynitrite, contributes to the myocardial contractile dysfunction associated with myocardial ischemia and reperfusion.

In contrast with these reports, others have found that peroxynitrite can mediate a number of physiological processes that may be beneficial and can potentially result in cellular protection. For example, $\mathrm{ONOO}^{-}$produces vascular relaxation in isolated dog and human coronary arteries $(24,25)$. Additionally, Wu et al. (26) have demonstrated that $\mathrm{ONOO}^{-}$ relaxes pulmonary arteries in vitro. Furthermore, $\mathrm{ONOO}^{-}$is a 
potent inhibitor of platelet aggregation (27). Despite numerous investigations into the biological effects of $\mathrm{ONOO}^{-}$, very little is actually known regarding the actions of this free radical species on the function of polymorphonuclear leukocytes. Accordingly, we sought to determine the effects of physiologically relevant concentrations of $\mathrm{ONOO}^{-}$on $\mathrm{PMN}_{-}$-endothelial cell interactions both in vitro and in vivo. More specifically, we investigated the effects of nanomolar concentrations of $\mathrm{ONOO}^{-}$on PMN adherence to rat superior mesenteric artery in vitro as well as on leukocyte-endothelial interactions in postcapillary venules in vivo. Finally, we investigated the role of $\mathrm{ONOO}^{-}$on PMN-mediated myocardial reperfusion injury in isolated perfused rat hearts.

\section{Methods}

Peroxynitrite. Peroxynitrite was obtained from the Alexis Corp. (San Diego, CA), prepared fresh, and shipped via express mail and stored at $-80^{\circ} \mathrm{C}$. The peroxynitrite was synthesized from acidified nitrite and hydrogen peroxide according to Beckman et al. (28). The concentration of peroxynitrite was monitored each day before use by measuring the increase in absorbance at $302 \mathrm{~nm}$ after the addition of $5 \mu \mathrm{l}$ of peroxynitrite in $3 \mathrm{ml}$ of $1 \mathrm{~N}$ sodium hydroxide at $\mathrm{pH}$ 12. In addition, peroxynitrite was also obtained as a gift from Dr. Harry Ischiropoulos at the University of Pennsylvania, which was used on the day it was received and was periodically checked spectrophotometrically. Only $\mathrm{ONOO}^{-}$, which was verified to be $>95 \%$ of the stipulated concentration, was used in these studies. To account for the effects of nitrite, hydrogen peroxide, and sodium chloride, we used a decomposed form of peroxynitrite prepared from the same stock as the active form of peroxynitrite (Alexis Corp.). In addition, $\mathrm{NaOH}$ titrated to $\mathrm{pH} 12$ or physiological buffers at the same $\mathrm{pH}$ as $\mathrm{ONOO}^{-}$(i.e., $\mathrm{pH}$ 8.4 , in vivo) were used as controls to account for the effects of $\mathrm{pH}$ on the various physiological preparations.

Vascular reactivity of rat aorta. Rats were anesthetized with sodium pentobarbital (40 mg/kg; Abbott Laboratories Diagnostic Division, Chicago, IL); a median sternotomy was performed and the thoracic aorta was isolated and placed in warm Hepes buffer consisting of (in mmol/liter): $\mathrm{NaCl}, 145$; Hepes, 10 ; glucose, $5.5 ; \mathrm{KCl}, 4.8 ; \mathrm{CaCl}_{2}$, $1.75 ; \mathrm{MgSO}_{4}, 1.2 ; \mathrm{KH}_{2} \mathrm{PO}_{4}, 1.2$; and disodium EDTA, 0.03. The surrounding connective tissue was removed from the aorta, which was cut into rings $2-3 \mathrm{~mm}$ in length. The rings were then mounted on stainless steel hooks, suspended in 7-ml tissue baths containing Hepes buffer, and aerated with $95 \% \mathrm{O}_{2}$ and $5 \% \mathrm{CO}_{2}$. Force displacement transducers (FT-03; Grass Instrument Co., Quincy, MA) were used to measure changes in developed force, which were recorded on an oscillographic recorder (Model 7; Grass Instrument Co.). A resting force of $1 \mathrm{~g}$ was applied to the aortic rings, and they were then allowed to equilibrate for $90 \mathrm{~min}$ at $37^{\circ} \mathrm{C}$, during which time the buffer in the organ bath was replaced every $10 \mathrm{~min}$. A resting stable contraction was obtained by addition of $10 \mathrm{nM}$ 9,11-methanoepoxy $\mathrm{PGH}_{2}$ (BIOMOL Research Laboratories Inc., Plymouth Meeting, PA). After addition of $5 \mu \mathrm{M} \mathrm{ONOO}^{-}, 100 \mathrm{nM}$ acetylcholine chloride (Sigma Chemical Co., St. Louis, MO) was added to several of the ring baths to determine the ability of an endothelium-dependent dilator to relax the aortic rings in the presence of $\mathrm{ONOO}^{-}$. After two to three washouts, most of the rings were tested with $\mathrm{ONOO}^{-}(500 \mathrm{nM}-50 \mu \mathrm{M})$ at pH 12, and $\mathrm{NaNO}_{2}(0.1,1,10,100 \mu \mathrm{M}$; Sigma Chemical Co.). As controls, the same procedures were repeated using a $\mathrm{pH} 12 \mathrm{Hepes}$ solution and $\mathrm{pH}$-inactivated control $\mathrm{ONOO}^{-}$(Alexis Corp.).

Neutrophil adherence to superior mesenteric artery endothelium. Rats received a $10-\mathrm{ml}$ injection of $0.5 \%$ glycogen i.p. (Sigma Chemical Co.). $18 \mathrm{~h}$ later, the rats were anesthetized with ethyl ether. The neutrophils were then collected by peritoneal lavage in PBS and centrifuged at $3,000 \mathrm{rpm}$ at $4^{\circ} \mathrm{C}$ for $10 \mathrm{~min}$. The neutrophils were again washed in PBS, isolated and labeled with a Zynaxis PKH-2 cell linker (Sigma Immunochemicals, St. Louis, MO) as described previously (29).
Segments of the superior mesenteric artery (SMA) ${ }^{1}$ were removed from rats, placed in warmed Krebs-Henseleit (K-H) solution containing (mM): $118 \mathrm{NaCl}, 4.74 \mathrm{KCl}, 2.45 \mathrm{CaCl}_{2}, 1.19 \mathrm{KH}_{2} \mathrm{PO}_{4}, 1.19$ $\mathrm{MgSO}_{4}, 12.5 \mathrm{NaHCO}_{3}$, and cleaned of all external adipose and loose connective tissue. Segments were then sectioned into 2-3-mm rings, opened, and placed into wells containing $2 \mathrm{ml} \mathrm{K}-\mathrm{H}+2 \%$ BSA solution. SMA arterial segments were incubated with either $2 \mathrm{U} / \mathrm{ml}$ thrombin (Sigma Immunochemicals) or $100 \mu \mathrm{M} \mathrm{H}_{2} \mathrm{O}_{2}$ for $10 \mathrm{~min}$ at $37^{\circ} \mathrm{C}$ to induce $\mathrm{P}$-selectin surface expression on the endothelium. $\mathrm{ONOO}^{-}(100 \mathrm{nM}$ and $1 \mu \mathrm{M})$ was added 3 min before the addition of thrombin or $\mathrm{H}_{2} \mathrm{O}_{2}$.

Labeled PMNs ( $10^{6}$ cells) and rat SMA arterial segments were incubated for $20 \mathrm{~min}$ at $37^{\circ} \mathrm{C}$ and the arterial segments were washed in $\mathrm{K}-\mathrm{H}$ buffer and placed endothelial side up on microscope slides. The number of adherent PMNs was counted using epifluorescence microscopy (Nikon Diaphot; Nikon Inc., Garden City, NY). Five different fields of each endothelial surface were counted and the results expressed as adherent PMNs $/ \mathrm{mm}^{2}$ of endothelial surface as previously described (29).

Intravital microscopy. Male Sprague-Dawley rats, weighing 250$275 \mathrm{~g}$, were anesthetized with sodium pentobarbital $(40 \mathrm{mg} / \mathrm{kg})$ administered intraperitoneally. A tracheotomy was performed to maintain a patent airway throughout the experiment. The left carotid artery was cannulated to monitor mean arterial blood pressure on an oscillographic recorder using a pressure transducer (Statham P23AC; Gould Inc., Cleveland, OH). A jugular vein was also cannulated for administration of supplemental sodium pentobarbital, as needed, to maintain a surgical plane of anesthesia throughout the experiment.

The abdominal cavity was opened via a midline laparotomy and a loop of ileal mesentery was exteriorized through the midline incision and placed in a temperature controlled fluid-filled plexiglass chamber for observation of the mesenteric microcirculation via intravital microscopy, according to previously described methods $(30,31)$.

The rats were allowed to stabilize for 20-30 min after surgery, and then a $30-50 \mu \mathrm{m}$ diameter postcapillary venule was chosen for observation. A baseline recording was made to establish basal values for leukocyte rolling and adherence. Video recordings were made at 30 , 60,90 , and $120 \mathrm{~min}$ after initiation of superfusion for quantification of leukocyte rolling and adherence. The mesentery was then superfused with $N^{\mathrm{G}}$-nitro-L-arginine-methyl ester (L-NAME) $(50 \mu \mathrm{M}$; Sigma Chemical Co. $)$ or thrombin $(0.5 \mathrm{U} / \mathrm{ml})$ in modified Krebs-Henseleit solution for $120 \mathrm{~min}$. Peroxynitrite $(0.8 \mu \mathrm{M}$ diluted in 8.4-pH K-H buffer) was directly applied to the exposed mesenteric microvasculature by a 120 -min superfusion at a flow rate of $25 \mu \mathrm{l} / \mathrm{min}$. Immediately thereafter, L-NAME or thrombin superfusion of mesentery was initiated. In five additional rats, the $\mathrm{ONOO}^{-}$superfusion was terminated after $30 \mathrm{~min}$, and fresh $0.5-\mathrm{U} / \mathrm{ml}$ thrombin superfusion continued for an additional $90 \mathrm{~min}$.

The number of rolling and adhered leukocytes were determined off-line by playback of the videotape. Leukocytes were considered to be rolling if they were moving at a velocity significantly slower than that of red blood cells. Leukocyte rolling is expressed as the number of cells moving past a designated point per minute (i.e., leukocyte flux). A leukocyte was judged to be adherent if it remained stationary

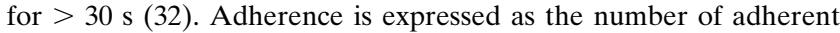
leukocytes/100 $\mu \mathrm{m}$ of vessel length. Red blood cell velocity (V) and venular diameter $(D)$ were used to calculate venular wall shear rate $(\mathrm{g})$ employing the formula $\mathrm{g}=8(\mathrm{Vmean} / \mathrm{D})(\mathrm{Vmean}=\mathrm{Vrbc} / 1.6)(32)$.

Immunohistochemistry. Immunohistochemical localization of $\mathrm{P}$-selectin was determined in intestinal venules after intravital microscopy was completed. Both the superior mesenteric artery and superior

1. Abbreviations used in this paper: $\mathrm{dP} / \mathrm{dt}$ max, maximal rate of development of left ventricular presence; K-H, Krebs-Henseleit solution; L-NAME, $N^{\mathrm{G}}$-nitro-L-arginine-methyl ester; LVDP, left ventricular developed pressure; MPO, myeloperoxidase; SMA, superior mesenteric artery. 
mesenteric vein were then rapidly cannulated for perfusion fixation of the small bowel. The ileum was first washed free of blood by perfusion with Krebs-Henseleit buffer warmed to $37^{\circ} \mathrm{C}$ and bubbled with $95 \% \mathrm{O}_{2}$ and $5 \% \mathrm{CO}_{2}$. Once the venous perfusate was free of red blood cells, perfusion was initiated with iced $4 \%$ paraformaldehyde mixed in phosphate-buffered $0.9 \% \mathrm{NaCl}$ for $5 \mathrm{~min}$. A 3-4-cm-long segment of ileum was isolated from the perfused intestine and fixed in $4 \%$ paraformaldehyde for $90 \mathrm{~min}$ at $4^{\circ} \mathrm{C}$. The ileum was then cut into rings, and the tissue dehydrated using graded acetone washes at $4^{\circ} \mathrm{C}$. Tissue sections were embedded in plastic (Immunobed; Polysciences Inc., Warrington, PA), and $4-\mu \mathrm{m}$-thick sections were cut and transferred to Vectabond-coated slides (Vector Laboratories, Inc., Burlingame, CA) and immunohistochemical localization of P-selectin was accomplished using the avidin-biotin immunoperoxidase technique, as previously described $(29,33)$. Positive staining was defined as a venule displaying brown reaction product on $>50 \%$ of the circumference of its endothelium. 50 venules per tissue sample were examined and the percentage of positive staining venules was tallied in three to four rats per group.

Isolated heart experiments. Male Sprague-Dawley rats (250 to $300 \mathrm{~g}$ ) were heparinized with 1,000 U sodium heparin (Abbott Laboratories Diagnostic Division) and anesthetized with $40 \mathrm{mg} / \mathrm{kg}$ sodium pentobarbital i.p. The hearts were rapidly excised, the ascending aorta was cannulated, and retrograde perfusion was initiated. The hearts were perfused with a Krebs bicarbonate perfusate of (in mmol/liter): glucose, 17; sodium chloride, 120; sodium bicarbonate, 25; calcium chloride, 2.5; EDTA, 0.5; potassium chloride, 5.9; and magnesium chloride, 1.2 at $37^{\circ} \mathrm{C}$ and a constant pressure of $80 \mathrm{mmHg}$. The perfusate was bubbled with $95 \% \mathrm{O}_{2}-5 \% \mathrm{CO}_{2}$. Two sidearms in the perfusion line located just proximal to the heart cannula allowed infusion of PMNs and plasma directly into the heart. To assess contractile function, a microtip catheter transducer (Millar Instruments Inc., Houston, TX) was inserted directly into the left ventricular cavity as reported previously (7). Left ventricular pressures, maximal rate of development of left ventricular pressure $(+\mathrm{dP} / \mathrm{dt} \max ),-\mathrm{dP} / \mathrm{dt} \min$, coronary flow, and heart rate were recorded using a Mac Lab data acquisition system (ADI Diagnostics Inc., Rexdale, Ontario, Canada) in conjunction with a Macintosh 7200 computer (Apple Computers, Cupertino, CA).

Rat plasma. Whole rat blood was obtained by performing an open-chest intracardiac puncture using a $10-\mathrm{ml}$ plastic syringe with a 20-gauge needle (Becton Dickinson and Co., Franklin Lakes, NJ) containing 2,000 U sodium heparin. To obtain platelet-poor plasma, the whole blood was immediately spun in a refrigerated centrifuge (GSGR; Beckman Instruments, Inc., Fullerton, CA) at 3,000 rpm for $25 \mathrm{~min}$. The plasma layer was collected and stored at $4^{\circ} \mathrm{C}$ until it was used in the isolated perfused heart (i.e., within $1 \mathrm{~h}$ ).

Experimental protocol. After a 15-min stabilization period, baseline left ventricular developed pressure (LVDP), $+\mathrm{dP} / \mathrm{dt}$ max, and coronary flow were measured every $5 \mathrm{~min}$ for $15 \mathrm{~min}$ to ensure complete equilibration of the hearts. Flow of Kreb's perfusate was stopped, creating global, zero-flow ischemia for $20 \mathrm{~min}$. Reperfusion of the hearts was instituted by the complete restoration of flow of buffer to the heart. At $5 \mathrm{~min}$ of reperfusion, $10^{8}$ rat PMNs isolated as described previously were infused into the hearts in combination with $5.0 \mathrm{ml}$ of freshly isolated rat plasma. The PMN-plasma mixture was infused directly into the hearts via a set of side ports situated in the perfusion line just proximal to the aorta over a 5-min period. The PMNs were suspended in 5.0-ml of Krebs buffer contained in a 5.0-ml syringe and the plasma was placed in a separate $5.0-\mathrm{ml}$ syringe. $\mathrm{ONOO}^{-}$was added to the plasma syringe just before infusion. The hearts were allowed to reperfuse for a total of $45 \mathrm{~min}$, during which time data were collected every $5 \mathrm{~min}$ for the first $30 \mathrm{~min}$ and at the 45min time point.

Determination of cardiac tissue myeloperoxidase. Myocardial tissue myeloperoxidase (MPO), an enzyme occurring virtually exclusively in neutrophils, was determined as described previously $(34,35)$. $1 \mathrm{U}$ of MPO is defined as that quantity of enzyme hydrolyzing 1 mmol of peroxide per minute at $25^{\circ} \mathrm{C}$. The assays were performed without knowledge of the group to which each sample originated.

Statistical analysis. All data are presented as means \pm SEM. Data were compared by ANOVA using post-hoc analysis with Fisher's corrected $t$ test. All data on leukocyte rolling and adherence, arterial blood pressure, shear rates, coronary flow, and left ventricular function were analyzed by ANOVA incorporating repeated measures. $P \leq 0.05$ was considered statistically significant.

\section{Results}

Vascular reactivity of rat aorta. The experiments investigating the effect of $\mathrm{ONOO}^{-}$on vascular tone in isolated rings of rat aorta are summarized in Fig. 1. Addition of $\mathrm{ONOO}^{-}$at a concentration of $5 \mu \mathrm{M}$ produced a $6.5 \pm 3.8 \%$ relaxation $(P=\mathrm{NS})$ of rat aorta and $50 \mu \mathrm{M}$ produced a $37.7 \pm 9.3 \%$ relaxation of rat aortic rings $(P<0.05$ vs. $\mathrm{NaOH}$ at $\mathrm{pH} 12$ or decomposed $\mathrm{ONOO}^{-}$). We also investigated the effects of $50-500 \mathrm{nM}$ of $\mathrm{ONOO}^{-}$on the vascular tone of the aorta and did not observe any detectable responses (data not shown). Finally, administration of either $\mathrm{pH}$-inactivated $\mathrm{ONOO}^{-}$or $\mathrm{NaOH}$ at $\mathrm{pH} 12$ had no significant effect on the vascular tone of rat aortic rings. Thus, $\mathrm{ONOO}^{-}$in the micromolar range exerted a significant vasorelaxant effect in isolated vascular tissue. Administration of $100 \mathrm{nM}$ acetylcholine after addition of $5 \mu \mathrm{M} \mathrm{ONOO}^{-}$resulted in a marked endothelium-dependent vasorelaxation of $68 \pm 8 \%(P<0.01)$ indicating that concentrations of $\mathrm{ONOO}^{-}$ up to $5 \mu \mathrm{M}$ do not impair the release of NO from the endothelium.

In vitro adherence of PMNs to superior mesenteric artery endothelium. Thrombin stimulation of isolated SMA resulted in a marked increase in the adhesion of unstimulated rat PMNs to isolated rat SMA endothelium (Fig. 2, top). The number of adherent PMNs $/ \mathrm{mm}^{2}$ increased sevenfold in thrombin-stimulated SMA endothelium compared with control SMA endothelium. ONOO ${ }^{-}(100 \mathrm{nM})$ reduced $\mathrm{PMN}$ adhesion to thrombin-stimulated SMA segments by $58 \%(P<0.01$ vs. thrombin alone) and $\mathrm{ONOO}^{-}(1 \mu \mathrm{M})$ reduced $\mathrm{PMN}$ adhesion to $63 \%$ ( $P<0.01$ vs. thrombin alone). Comparable results

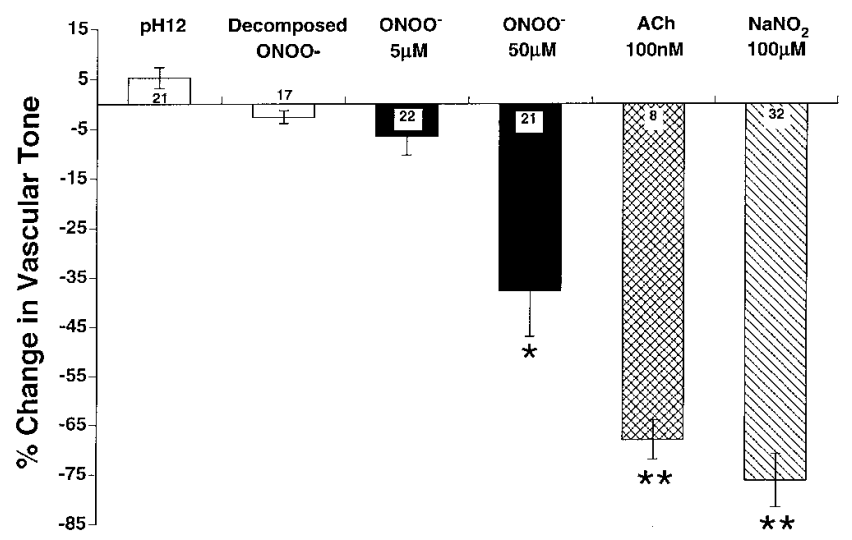

Figure 1. Vasorelaxation of isolated rat aortic rings to ONOO (5 and $50 \mu \mathrm{M}$ ), previously decomposed $\mathrm{ONOO}^{-}, \mathrm{NaOH}$ titrated to $\mathrm{pH} 12$, acetylcholine $(A C h) 100 \mathrm{nM}$, and acidified sodium nitrite $\left(\mathrm{NaNO}_{2}\right.$ at $\left.\mathrm{pH} 2\right)$. $* P<0.05$ and $* * P<0.01$ vs. $\mathrm{NaOH}$ or decomposed $\mathrm{ONOO}^{-}$. Numbers in the bars are the numbers of aortic rings studied. 

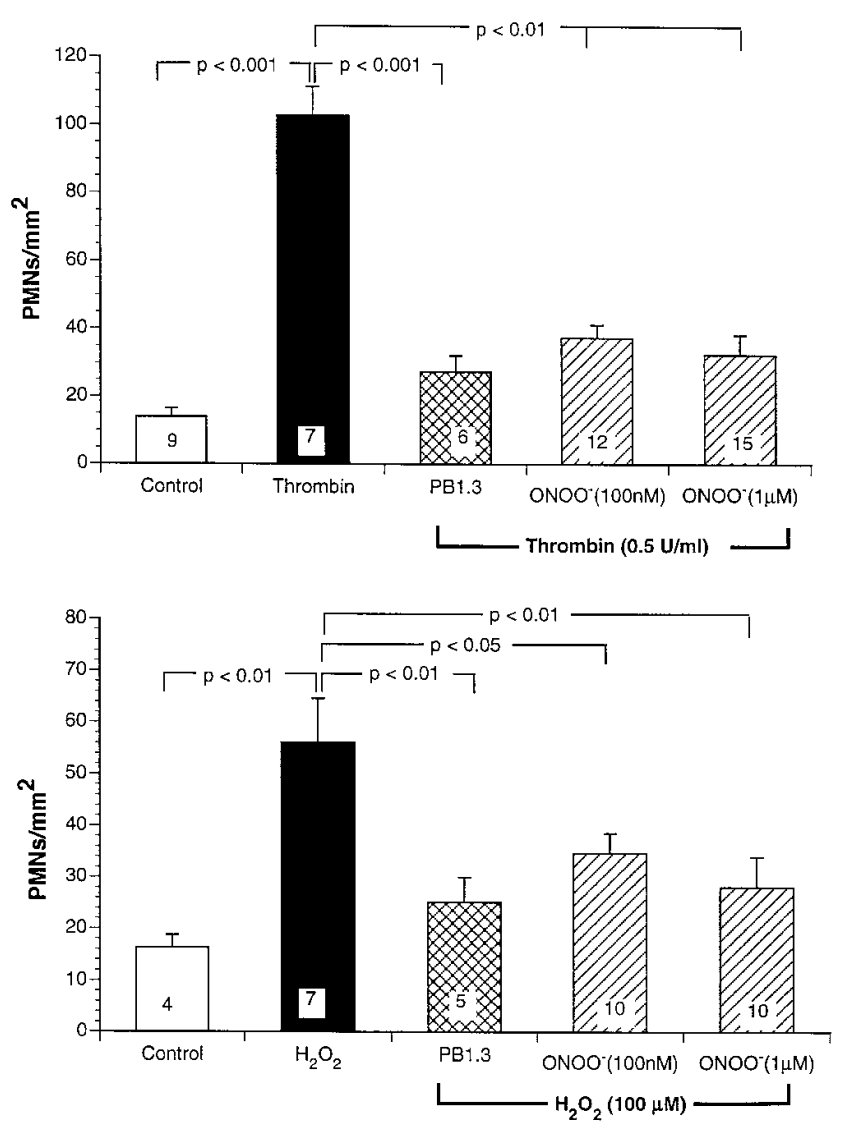

Figure 2. Adherence of rat neutrophils (PMNs) to thrombin- or $\mathrm{H}_{2} \mathrm{O}_{2}$-stimulated superior mesenteric endothelium in vitro. $\mathrm{ONOO}^{-}$ $(100 \mathrm{nM}$ and $1 \mu \mathrm{M})$ significantly attenuated PMN adherence compared with either thrombin alone $(P<0.01$, top $)$ or $\mathrm{H}_{2} \mathrm{O}_{2}$ alone $(P<0.01$, bottom $)$. The anti-P-selectin monoclonal antibody $(P B 1.3)$ also inhibited PMN adherence $(P<0.001$ to thrombin or $P<0.01$ to $\mathrm{H}_{2} \mathrm{O}_{2}$ ). All values are means \pm SEM. Numbers in the bars are numbers of SMA segments tested.

were obtained with $100 \mu \mathrm{M} \mathrm{H}_{2} \mathrm{O}_{2}$ as the endothelial stimulant (Fig. 2, bottom). Thus, $\mathrm{ONOO}^{-}$significantly attenuated the adhesion of unstimulated rat PMNs to thrombin-stimulated superior mesenteric vascular endothelium in vitro.

Intravital microscopy of the rat mesentery. Data for leukocyte rolling and adherence to mesenteric postcapillary venules are summarized in Fig. 3, $A$ and $B$. In the present study, we examined venules ranging from $43 \pm 6.7$ to $51 \pm 4.3 \mu \mathrm{m}$ in diameter and there were no differences in venular diameter between any of the groups studied. Similarly, the venular shear rates were very similar in all of the study groups, ranging from $553 \pm 30$ to $614 \pm 41 \mathrm{~s}^{-1}$. Thrombin $(0.5 \mathrm{U} / \mathrm{ml})$ markedly increased leukocyte rolling at $60-120 \mathrm{~min}$ after administration (Fig. 3 A). Addition of $\mathrm{ONOO}^{-}(800 \mathrm{nM})$ significantly attenuated the increase in leukocyte rolling $(P<0.05$ or $P<0.01$ vs. thrombin alone) at 30-120 min. In contrast, the addition of $\mathrm{ONOO}^{-}$under control conditions had no significant effect on leukocyte rolling in the rat mesentery. Similarly, leukocyte adherence was significantly increased at 30-120 min after thrombin stimulation of the mesentery, and this response was virtually abolished by $800 \mathrm{nM} \mathrm{ONOO}{ }^{-}$. In parallel experimental studies, we investigated the effects of $\mathrm{ONOO}^{-}(800 \mathrm{nM})$ on
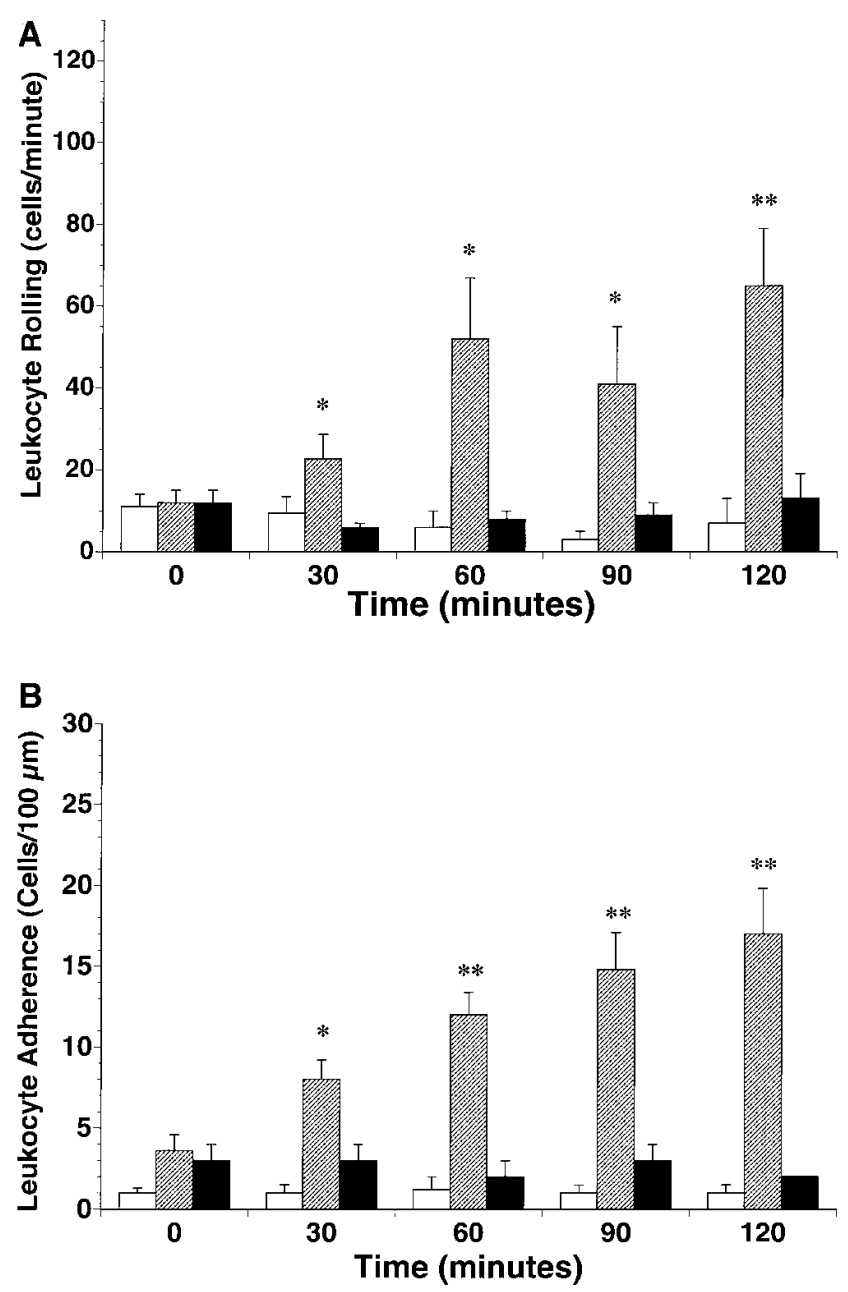

Figure 3. (A) Leukocyte rolling in the rat mesenteric venules observed using intravital microscopy. Baseline values and values every $30 \mathrm{~min}$ after thrombin $(\square)(0.5 \mathrm{U} / \mathrm{ml})$ administration are shown. Thrombin markedly enhanced leukocyte rolling along the venular endothelium from 30 to $120 \mathrm{~min}$, which was markedly attenuated by superfusion of the mesentery with $\mathrm{ONOO}^{-}(\mathbf{\square})(800 \mathrm{nM}) . * P<0.05$; $* P<0.01$ vs. baseline or $\mathrm{ONOO}^{-}$alone $(\square)$. (B) Leukocyte adherence to rat mesenteric postcapillary venules expressed as the number of leukocytes adhered to $100-\mu \mathrm{m}$ length of venule, as observed by intravital microscopy. All values are means \pm SEM. Thrombin $(\square)(0.5$ $\mathrm{U} / \mathrm{ml}$ ) significantly increased leukocyte adherence, which was inhibited by $\mathrm{ONOO}^{-}$30-120 min after thrombin administration (ם), $* P<0.05 ; * * P<0.01$ vs. baseline or $\mathrm{ONOO}^{-}$alone $(\square)$.

leukocyte rolling and adhesion after induction of P-selectin with L-NAME $(50 \mu \mathrm{M})$. $\mathrm{ONOO}^{-}$also significantly inhibited the L-NAME-mediated increase in leukocyte rolling and adherence to a comparable degree to its effects on thrombinstimulated mesenteries. Thus, $50 \mu \mathrm{M}$ L-NAME increased leukocyte rolling fivefold, and leukocyte adherence sevenfold at $120 \mathrm{~min}$. Addition of $800 \mathrm{nM} \mathrm{ONOO}^{-}$with L-NAME reduced leukocyte rolling at $120 \mathrm{~min}$ to $12 \pm 4$ and attenuated adherence to $1.5 \pm 0.3(P<0.01$ from L-NAME alone for both rolling and adherence). We also tested the effects of $\mathrm{pH}$-inactivated $\mathrm{ONOO}^{-}$on the thrombin-mediated increases in leukocyte rolling and adherence and determined that this decomposed form of peroxynitrite had no effect on leukocyte-endothelial 


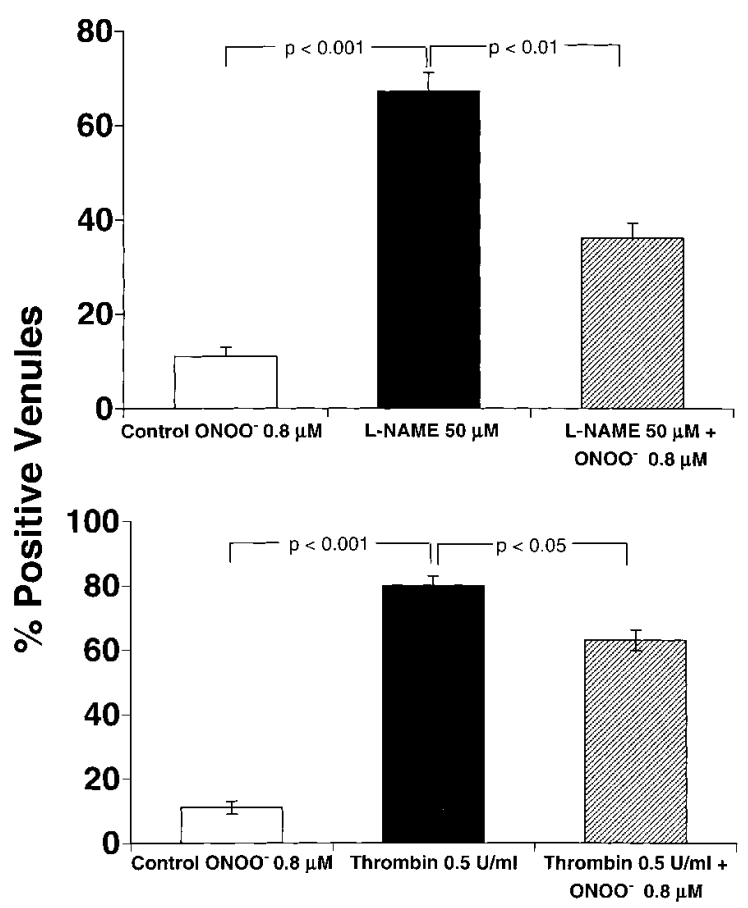

Figure 4. Quantification of immunohistochemical staining of P-selectin in rat intestinal venules after administration of L-NAME $(50 \mu \mathrm{M})$ or thrombin $(0.5 \mathrm{U} / \mathrm{ml})$. $\mathrm{ONOO}^{-}(800 \mathrm{nM})$ significantly attenuated the surface expression of P-selectin. 50 venules were counted in each rat sample and 10 samples were analyzed in each group of three to four rats.

cell interactions. Under these conditions, leukocyte rolling increased from $12 \pm 4.6$ at baseline to $69 \pm 15$ cells $/ \mathrm{min}$ at $120 \mathrm{~min}$, and adherence increased from $2.8 \pm 0.9$ at baseline to $16 \pm 3.2$ cells $/ 100 \mu \mathrm{m}$ at $120 \mathrm{~min}$. Clearly, decomposed $\mathrm{ONOO}^{-}$did not alter leukocyte adhesive interactions in mesenteric venules. Finally, we tested the reversibility of the $\mathrm{ONOO}^{-}$effect on leukocyte rolling and adherence. Five additional rats were superfused with $0.5 \mathrm{U} / \mathrm{ml}$ thrombin along with $800 \mathrm{nM} \mathrm{ONOO}^{-}$. After $30 \mathrm{~min}$, leukocyte rolling was only $17 \pm 2.2 \mathrm{WBCs} / \mathrm{min}$ and leukocyte adherence was only $3.1 \mathrm{WBCs} / 100 \mu \mathrm{m}$ venule. We then terminated the $\mathrm{ONOO}^{-}$superfusion and added fresh thrombin. At $120 \mathrm{~min}$, leukocyte rolling had increased to $54 \pm 1.4 \mathrm{WBCs} / \mathrm{min}$ and leukocyte adherence increased to $12.5 \pm 0.9 \mathrm{WBCs} / 100 \mu \mathrm{m}$. These values are both significantly elevated from the $30-\mathrm{min} \mathrm{ONOO}^{-}$value $(P<0.01)$, indicating that $\mathrm{ONOO}^{-}$does not irreversibly damage the leukocyte or the endothelial cell adhesion molecules.

Surface $P$-selectin expression in intestinal venules. Immunostaining was used to measure the extent of surface expression of P-selectin in rat intestinal venules after stimulation with either L-NAME $(50 \mu \mathrm{M})$ or thrombin $(0.5 \mathrm{U} / \mathrm{ml})$. Immunohistochemical data are expressed as the percentage of positive venules and are presented in Fig. 4. Basal expression of P-selectin was observed in $\sim 10 \%$ of all venules and this was significantly increased $\left(P<0.001\right.$ vs. control $\left.\mathrm{ONOO}^{-}\right)$to $70-80 \%$ in L-NAME and thrombin-stimulated mesenteries. Pretreatment with $\mathrm{ONOO}^{-}$significantly reduced the surface expression of P-selectin that was observed after stimulation with either L-NAME $(P<0.01)$ or thrombin $(P<0.05)$. These data, to-

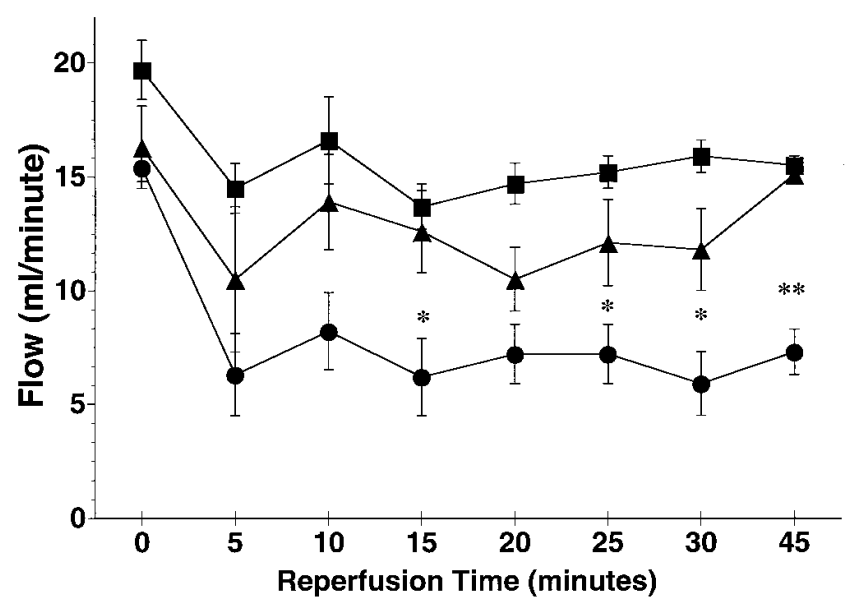

Figure 5. Postischemic coronary flow expressed in milliliters/minute in isolated perfused rat hearts subjected to $20 \mathrm{~min}$ of global ischemia and reperfusion. Ischemic hearts were reperfused in the presence $\left(+\mathrm{PMNs}, 10^{8}\right)(-\mathbf{O})$ or absence $(\boldsymbol{\square}-\boldsymbol{\square})$ of PMNs. In addition, $\mathrm{ONOO}^{-}(800 \mathrm{nM})$ was infused after ischemia and reperfusion + PMNs $(\boldsymbol{\Delta}-\boldsymbol{\Delta})$. All values are means \pm SEM of six to eight hearts in each group. ${ }^{*} P<0.05$ and $* * P<0.01$ between the two PMN groups. 0 , preischemic baseline.

gether with the leukocyte rolling and adherence data in the rat mesentery, clearly indicate that high nanomolar concentrations of $\mathrm{ONOO}^{-}$inhibit leukocyte-endothelial cell interactions in vivo by a P-selectin-dependent mechanism.

Ischemia-reperfusion of isolated rat hearts. To determine whether these effects of $\mathrm{ONOO}^{-}$attenuating leukocyte-endothelial interactions can translate into a meaningful effect in a carefully controlled model, we tested $\mathrm{ONOO}^{-}$in a well characterized model of myocardial ischemia reperfusion. Accordingly, we perfused rat hearts that were subjected to $20 \mathrm{~min}$ of

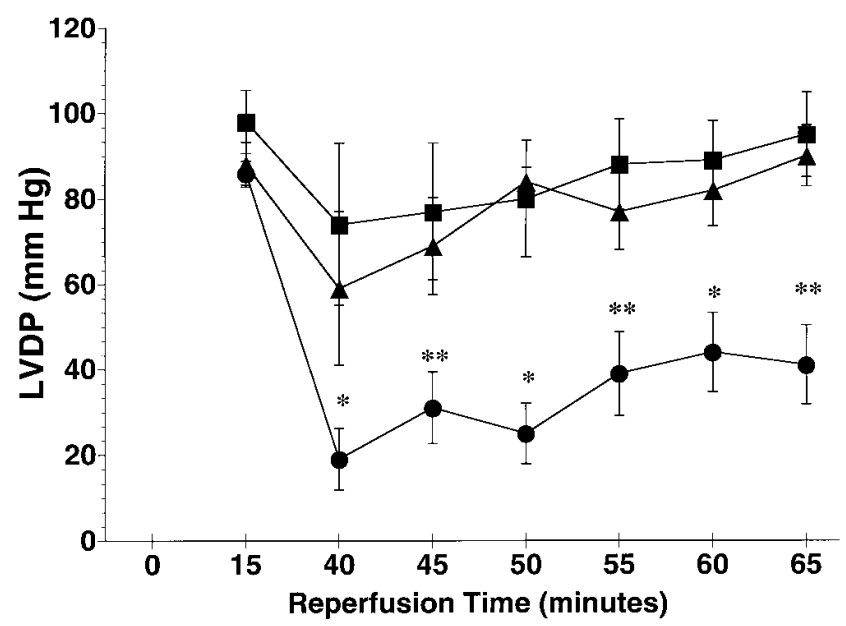

Figure 6. Left ventricular developed pressure expressed in $\mathrm{mmHg}$ in rat hearts after ischemia and reperfusion. Ischemic hearts were reperfused in the presence (-) or absence ( $-\mathbf{-})$ of PMNs. In addition, $\mathrm{ONOO}^{-}(800 \mathrm{nM})$ was infused after ischemia and reperfusion + PMNs $(\boldsymbol{\Delta}-\mathbf{\Delta})$. ONOO $^{-}$treatment markedly improved postischemic LVDP throughout reperfusion. $* P<0.05$ and $* * P<0.01$ between the two PMN groups. 0, preischemic baseline. 


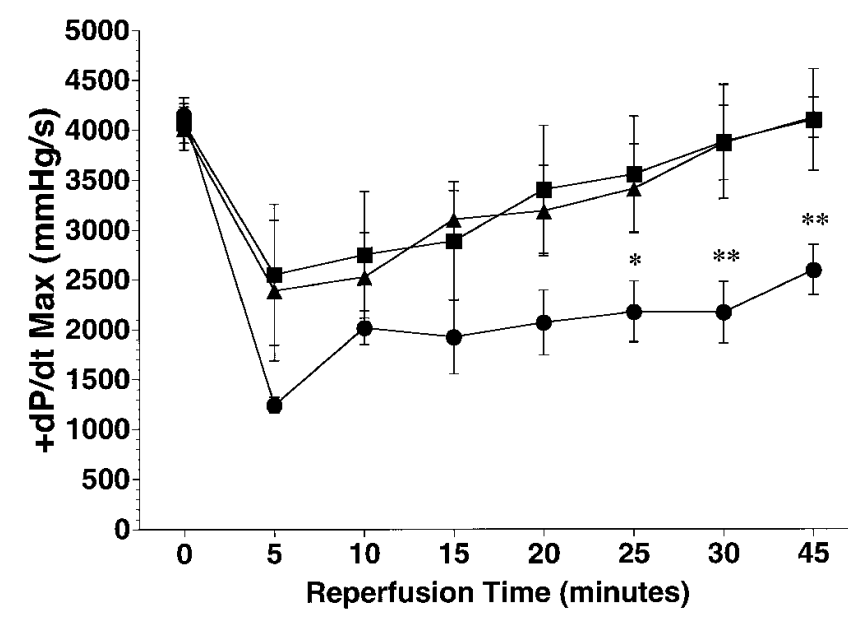

Figure 7. The peak of the first derivative of LVDP $(+\mathrm{dP} / \mathrm{dt}$ max $)$ in hearts subjected to ischemia and reperfusion. Ischemic hearts were reperfused in the presence $(-\mathbf{0})$ or absence $(\boldsymbol{\square}-\mathbf{\square})$ of PMNs. In addition, $\mathrm{ONOO}^{-}(800 \mathrm{nM})$ was infused after ischemia and reperfusion + PMNs $\left(\boldsymbol{\Delta}^{-} \boldsymbol{\Lambda}\right)$. Hearts receiving $\mathrm{ONOO}^{-}$demonstrated significantly better recovery in $+\mathrm{dP} / \mathrm{dt}$ max compared with untreated hearts. ${ }^{*} P<0.05$ and $* * P<0.01$ between the two PMN groups. 0 , preischemic baseline.

ischemia and 45 min of reperfusion with or without rat PMNs $\left(10^{8}\right)$. Physiological data recording included measurement of coronary flow, LVDP, and left ventricular (LV) + dP/dt max. These data are presented in Figs. 5-7. Hearts subjected to ischemia and reperfusion in the absence of PMNs exhibited recovery of all physiological variables to baseline levels by 45 min of reperfusion. In contrast, infusion of rat PMNs at 5-10 min after reperfusion resulted in a significant and sustained reduction in coronary flow (Fig. 5) as well as a significant impairment of LVDP (Fig. 6) and LV $+\mathrm{dP} / \mathrm{dt}$ (Fig. 7) throughout the entire 45-min reperfusion period. In contrast,

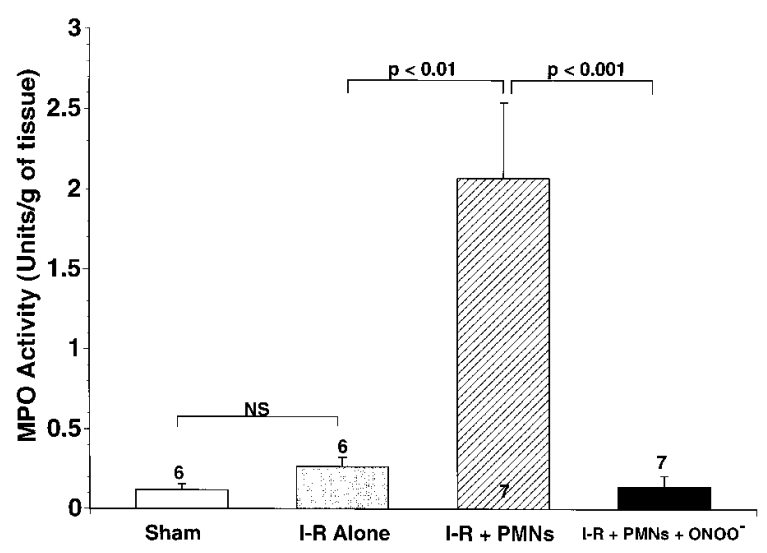

Figure 8. Cardiac myeloperoxidase activity in tissue samples from sham-operated nonischemic and ischemic-reperfused hearts expressed in units per gram of wet tissue weight. All values are means \pm SEM. Numbers in bars represent the numbers of hearts analyzed. Nonischemic (Sham) and I-R hearts perfused without PMNs (I-R Alone) did not exhibit significant MPO activity. I-R + PMNperfused hearts developed very high MPO activity that was significantly attenuated by $\mathrm{ONOO}^{-}$. infusion of peroxynitrite in the presence of PMNs resulted in a significant degree of cardioprotection in terms of coronary flow, LVDP, and $+\mathrm{dP} / \mathrm{dt}$ max. Thus, $\mathrm{ONOO}^{-}$preserved cardiac performance in the face of significant PMN challenge in the isolated, ischemic-reperfused rat heart.

Biochemical analysis of myeloperoxidase activities in ischemic-reperfused hearts was performed to assess myocardial PMN accumulation, and these results are shown in Fig. 8. In sham ischemic-reperfused hearts, cardiac MPO activity was low and similar to that observed in hearts subjected to ischemia and reperfusion without PMNs. However, cardiac MPO activity was elevated eightfold in ischemic-reperfused hearts receiving $\mathrm{PMN}$ infusion, and treatment with $\mathrm{ONOO}^{-}$ resulted in a dramatic reduction $(P<0.001)$ in cardiac MPO activity to control values. Histological analysis of heart tissue specimens was used to confirm the degree of PMN accumulation in ischemic-reperfused hearts. $\mathrm{ONOO}^{-}$attenuated the infiltration of PMNs into heart tissue as the number of PMNs/ $\mathrm{mm}^{2}$ of cross-sectional area of cardiac tissue was reduced from $154 \pm 10$ to $26 \pm 3(P<0.001)$, a sixfold reduction. Thus, $\mathrm{ONOO}^{-}$clearly protects the ischemic-reperfused rat heart to a large measure by inhibiting PMN accumulation in cardiac tissue.

\section{Discussion}

Previous reports have claimed that peroxynitrite is a toxic substance that contributes to tissue injury in a number of biological systems (36-38). Much of this previous work is based on high micromolar to millimolar concentrations of peroxynitrite studied in simple solutions or in isolated cells. In the present study, we provide important new evidence that nanomolar concentrations of $\mathrm{ONOO}^{-}$significantly inhibit leukocyteendothelial cell interactions both in vitro and in vivo. We found that $\mathrm{ONOO}^{-}$markedly inhibits the adhesion of isolated PMNs to thrombin-stimulated superior mesenteric artery endothelium, and attenuates leukocyte rolling and adherence on the mesenteric venular endothelium after stimulation of P-selectin surface expression either with thrombin or a nitric oxide synthesis inhibitor. In this setting, exogenously administered $\mathrm{ONOO}^{-}$significantly attenuated the upregulation of P-selectin on the surface of intestinal venules in vivo. Furthermore, we also determined that nanomolar concentrations of $\mathrm{ONOO}^{-}$ significantly reduced the extent of PMN accumulation in the ischemic-reperfused rat heart that was associated with markedly improved postischemic myocardial contractile function. All of these findings point toward a cytoprotective action of nanomolar concentrations of $\mathrm{ONOO}^{-}$related to attenuation of leukocyte-endothelium interactions.

The metabolism of nitric oxide is complex, and NO has been shown to interact with a number of oxygen-derived free radicals including superoxide to form $\mathrm{ONOO}^{-}$, which can then be protonated to form peroxynitrous acid, a relatively stable oxidant species $(18,19)$. It has been suggested that peroxynitrous acid can decompose spontaneously to form a potent oxidant (i.e., peroxynitrite) with reactive properties similar to that of hydroxyl radical (18-20). Despite the lack of any direct and conclusive evidence for the formation of $\mathrm{ONOO}^{-}$in vivo, a number of in vitro studies have reported toxic actions of $\mathrm{ONOO}^{-}$. The majority of studies reporting cytotoxic actions of $\mathrm{ONOO}^{-}$in vitro have employed very high micromolar to low millimolar concentrations of $\mathrm{ONOO}^{-}$in a variety of sys- 
tems. These in vitro studies have fueled considerable speculation that $\mathrm{ONOO}^{-}$is an important mediator of tissue injury. It is therefore not surprising that $\mathrm{ONOO}^{-}$has been implicated in the toxicity associated with pulmonary disorders $(20,21)$, myocardial ischemic injury (16), and apoptosis (39), as well as endotoxic and hemorrhagic shock states (22). Much of the evidence for the injurious actions of $\mathrm{ONOO}^{-}$is based on indirect evidence, and we are unaware of any study that has directly measured the production of $\mathrm{ONOO}^{-}$in vivo under normal or pathological conditions.

In contrast with these studies, nanomolar concentrations of $\mathrm{ONOO}^{-}$have been reported to exert physiological effects that result in vascular relaxation and inhibition of platelet aggregation. Villa et al. (40) reported that $\mathrm{ONOO}^{-}$induced a concentration-dependent coronary vasodilation in isolated perfused rat hearts with an $\mathrm{EC}_{50}$ of about $20 \mu \mathrm{M}$, a value similar to that observed in the present study in rat aortic rings. Furthermore, low micromolar concentrations of $\mathrm{ONOO}^{-}$can cause relaxation of isolated bovine pulmonary arteries concomitant with the production of NO (26). Indeed, $\mathrm{ONOO}^{-}(1-30 \mu \mathrm{M})$ decreases the vascular tone of isolated canine (24) and human coronary arteries (25). $\mathrm{ONOO}^{-}$is also a potent inhibitor of human platelets when administered at low micromolar concentrations in vitro $(27,41)$. Thus, $\mathrm{ONOO}^{-}$possesses a physiological profile similar to that of $\mathrm{NO}$ at nanomolar and low micromolar concentrations (42). This is an extremely important point since it is highly unlikely that $\mathrm{ONOO}^{-}$can be formed or accumulate in vivo at concentrations greater than $1-5 \mu \mathrm{M}$. This is because $\mathrm{ONOO}^{-}$forms from the equimolar interaction between NO and superoxide radicals (43). NO is formed normally at 1-20 $\mathrm{nM}(1,42)$, but can increase to higher levels in disease states. However, the half-life of $\mathrm{ONOO}^{-}$is about $1 \mathrm{~s}$, and the effective concentration of $\mathrm{ONOO}^{-}$would be in the nanomolar range even in disease states. Recently, Miles et al. (43) have shown that $\mathrm{ONOO}^{-}$forms optimally from equimolar concentrations of $\mathrm{NO}$ and superoxide, and that inequality of either precursor greatly limits production of $\mathrm{ONOO}^{-}$. Therefore, it is highly unlikely for $\mathrm{ONOO}^{-}$to achieve the high micromolar to millimolar concentrations that are necessary to exert significant toxic effects (44).

Recently, Mayer et al. (45) reported that $\mathrm{ONOO}^{-}$induced a pronounced increase in endothelial cell cyclic GMP levels and that in biological systems $\mathrm{ONOO}^{-}$causes S-nitrosation of cellular thiols resulting in NO-mediated cyclic GMP accumulation. It was also demonstrated (44) that $\mathrm{ONOO}^{-}$stimulated purified soluble guanylyl cyclase with a half-maximally effective concentration of $\sim 20 \mu \mathrm{M}$. In addition, $\mathrm{ONOO}^{-}$was found to react with sugars or other compounds containing alcohol groups to form $\mathrm{NO}$ donors that produce vasodilation and inhibit platelet aggregation (46). These data suggest that $\mathrm{ONOO}^{-}$can serve as an NO donor under physiological conditions and can thereby regulate vascular homeostasis by virtue of its ability to release NO. This effect would be consistent with the data presented in this report.

It is now well established that NO is a potent modulator of leukocyte adhesion to the endothelium (3-5). A number of previous studies have clearly demonstrated antineutrophil properties of NO in vivo as well as in vitro (5-8). Administration of authentic NO (47), NO donors $(7,8)$, or the NO precursor L-arginine $(48,49)$ have all proven to be highly beneficial in a number of inflammatory disease states including ischemiareperfusion injury. Furthermore, we have recently shown (5,
30) that NO inhibits the expression of P-selectin on endothelial cells. Recently, DeCaterina et al. (50) have shown that nitric oxide inhibits the expression of intercellular and vascular cell adhesion molecules-1, two other endothelial cell adhesion molecules. Inhibition of adhesion molecule expression is likely to be a key mechanism of the antileukocyte actions of NO. The results of the present study indicate that $\mathrm{ONOO}^{-}$can also interfere with the interactions between circulating leukocytes and the vascular endothelium, largely due to attenuating endothelial cell expression of P-selectin after stimulation with thrombin or L-NAME. The degree of attenuation of P-selectin upregulation in intestinal venules by $\mathrm{ONOO}^{-}$is less than would be predicted by the degree of inhibition of leukocyte rolling. This is probably due to the fact that we superfused $\mathrm{ONOO}^{-}$onto the mesentery where it could readily diffuse to mesenteric venules, but would not so readily reach more distant intestinal venules where the immunolocalization was studied. This is consistent with earlier findings with $\mathrm{NO}$ in this same preparation (30). Due to the potential NO-donating properties of $\mathrm{ONOO}^{-}$, it is likely that NO liberated from peroxynitrite is responsible for the inhibitory effects on P-selectin expression, but the precise mechanism of this immunomodulatory function of $\mathrm{ONOO}^{-}$remains to be determined.

We also obtained evidence that the nanomolar concentrations of $\mathrm{ONOO}^{-}$we employed did not produce endothelial injury. Thus, after exposure to $500 \mathrm{nM}$ and $5 \mu \mathrm{M} \mathrm{ONOO}^{-}$, rat aortic rings were able to respond nearly fully to acetylcholine, an endothelium-dependent vasodilator. Moreover, in the intravital microscopy studies, cessation of $\mathrm{ONOO}^{-}$superfusion after 30 min resulted in a marked upregulation of both leukocyte rolling and adherence, indicating that the leukocyte and endothelial cell adhesion molecules were functional. Thus, it appears that nanomolar concentrations of $\mathrm{ONOO}^{-}$are not acutely toxic to the endothelium.

In summary, we have demonstrated that nanomolar concentrations of $\mathrm{ONOO}^{-}$markedly inhibit leukocyte adhesion to vascular endothelium in several physiological systems. $\mathrm{ONOO}^{-}$inhibited leukocyte rolling and adhesion within mesenteric venules largely in response to P-selectin expression. In addition, peroxynitrite reduced the degree of neutrophil-induced myocardial dysfunction after ischemia and reperfusion of the myocardium. To our knowledge, this is the first study to support the concept that $\mathrm{ONOO}^{-}$inhibits the expression of P-selectin on endothelial cells and thereby reduces leukocyte rolling and subsequent firm adhesion of leukocytes to the endothelium. Since inhibition of leukocyte rolling has been found to be beneficial in ischemia reperfusion (51), these effects may be important in understanding the role of nitric oxide and its metabolites in pathophysiological states including ischemia-reperfusion injury and circulatory shock. This study is also the first to show that $\mathrm{ONOO}^{-}$protects against $\mathrm{PMN}$-induced myocardial injury.

\section{Acknowledgments}

The authors are very grateful to Robert Craig for his expert technical assistance during the course of these experimental studies. In addition, the authors would like to thank Dr. Harry Ischiropoulus for the generous supply of peroxynitrite.

This study was supported in part by a grant from the National Institutes of Health, GM-45434 (A.M. Lefer), and by a grant from the Juvenile Diabetes Foundation, 195065 (D.J. Lefer). 


\section{References}

1. Kelm, M., and J. Schrader. 1990. Control of coronary vascular tone by nitric oxide. Circ. Res. 66:1561-1575.

2. Radomski, M.W., R.M.J. Palmer, and S. Moncada. 1987. The anti-aggregating properties of vascular endothelium: interactions between prostacyclin and nitric oxide. Br. J. Pharmacol. 92:639-646.

3. Kubes, P., M. Suzuki, and D.N. Granger. 1991. Nitric oxide: an endogenous modulator of leukocyte adhesion. Proc. Natl. Acad. Sci. USA. 88:46514655.

4. Niu, X.-F., C.W. Smith, and P. Kubes. 1994. Intracellular oxidative stress induced by nitric oxide synthesis inhibition increases endothelial cell adhesion to neutrophils. Circ. Res. 74:1133-1140.

5. Gauthier, T.W., K.L. Davenpeck, and A.M. Lefer. 1994. Nitric oxide attenuates leukocyte-endothelial interaction via P-selectin in splanchnic ischemiareperfusion. Am. J. Physiol. 267:G562-G568.

6. Kurose, I., P. Kubes, R. Wolf, D.C. Anderson, J. Paulson, M. Miyasaka, and D.N. Granger. 1993. Inhibition of nitric oxide production: mechanisms of vascular albumin leakage. Circ. Res. 73:164-171.

7. Pabla, R., A.J. Buda, D.M. Flynn, S.A. Blesse, A.M. Shin, M.J. Curtis, and D.J. Lefer. 1996. Nitric oxide attenuates neutrophil-mediated myocardial contractile dysfunction after ischemia and reperfusion. Circ. Res. 78:65-72.

8. Siegfried, M.R., C. Carey, X.-L. Ma, and A.M. Lefer. 1992. Beneficial effects of SPM-5185, a cysteine-containing NO donor in myocardial ischemia-reperfusion. Am. J. Physiol. 263:H771-H777.

9. Rossaint, R.K., J. Falke, F. Lopez, K. Slama, U. Pison, and W.M. Zapol. 1993. Inhaled nitric oxide for the adult respiratory distress syndrome. N. Engl. J. Med. 328:399-405.

10. Guo, J.-P., M.M. Panday, M. Consigny, and A.M. Lefer. 1995. Mechanisms of vascular preservation by a novel NO donor following carotid artery injury. Am. J. Physiol. 269:H1122-H1131.

11. Cooke, J.P., A.H. Singer, P. Tsao, P. Zera, R.A. Rowan, and M.E. Billingham. 1992. Antiatherogenic effects of L-arginine in the hypercholesterolemic rabbit. J. Clin. Invest. 90:1168-1172.

12. Groves, P.H., M.J. Lewis, H.A. Cheadle, and W.J. Penny. 1993. SIN-1 reduces platelet adhesion and platelet thrombus formation in a porcine model of balloon angioplasty. Circulation. 87:590-597.

13. Wizemann, T.M., C.R. Gardner, J.D. Laskin, S. Quinones, S.K. Durham, N.L. Goller, S.T. Ohnishi, and D.L. Laskin. 1994. Production of nitric oxide and peroxynitrite in the lung during acute endotoxemia. J. Leukocyte Biol. 56:759-768.

14. Keaney, J.F., J.-C. Puyana, S. Francis, J.F. Loscalzo, J.S. Stamler, and J. Loscalzo. 1994. Methylene blue reverses endotoxin-induced hypotension. Circ. Res. 74:1121-1125.

15. Nava, E., R.M.J. Palmer, and S. Moncada. 1991. Inhibition of nitric oxide synthesis in septic shock: how much is beneficial. Lancet (N. Am. Ed.). 338: $1555-1556$

16. Schulz, R., and R. Wambolt. 1995. Inhibition of nitric oxide synthesis protects the isolated working rabbit heart from ischaemia-reperfusion injury. Cardiovasc. Res. 30:432-439.

17. Mathies, G., M.P. Sherman, G.D. Buckberg, D.M. Haybron, H.H. Young, and L.J. Ignarro. 1992. Role of L-arginine-nitric oxide pathway in myocardial reoxygenation injury. Am. J. Physiol. 262:H616-620.

18. Pryor, W.A., and G.L. Squadrito. 1995. The chemistry of peroxynitrite: a product from the reaction of nitric oxide and superoxide. Am. J. Physiol. 268: L699-L722.

19. Beckman, J.S., T.W. Beckman, J. Chen, P.A. Marshall, and B.A. Freeman. 1990. Apparent hydroxyl radical production by peroxynitrite: implications for endothelial injury from nitric oxide and superoxide. Proc. Natl. Acad. Sci. USA. 87:1620-1624.

20. Ischiropoulos, H., A.B. Al-Mehdi, and A.B. Fisher. 1995. Reactive species in ischemic rat lung injury: contribution of peroxynitrite. Am. J. Physiol. 269:L158-L164.

21. Kooy, N.W., J.A. Royall, Y.Z. Ye, D.R. Kelley, and J.S. Beckman. 1995. Evidence for in vivo peroxynitrite production in human acute lung injury. Am. J. Respir. Crit. Care Med. 151:1250-1254.

22. Szabo, C., A.L. Salzman, and H. Ischiropoulos. 1995. Peroxynitritemediated oxidation of dihydrorhodamine 123 occurs in early stages of endotoxic and hemorrhagic shock and ischemia-reperfusion injury. FEBS Lett. 372: 229-232.

23. Ischiropoulos, H., and A.B. Al-Mehdi. 1995. Peroxynitrite-mediated oxidative protein modifications. FEBS Lett. 364:279-282.

24. Liu, S., J.S. Beckman, and D.D. Ku. 1994. Peroxynitrite, a product of superoxide and nitric oxide, produces coronary vasorelaxation in dogs. J. Pharmacol. Exp. Ther. 268:1114-1121.

25. Ku, D.D., S. Liu, and J. Dai. 1995. Coronary vascular and antiplatelet effects of peroxynitrite in human tissues. Endothelium. 3:309-319.

26. Wu, M.N., K.A. Pritchard, P.M. Kaminski, R.P. Fayngersh, T.H. Hintze, and M.S. Wolin. 1994. Involvement of nitric oxide and nitrosothiols in relaxation of pulmonary arteries to peroxynitrite. Am. J. Physiol. 266:H2108-H2113.
27. Naseem, K.M., and K.R. Bruckdorfer. 1995. Hydrogen peroxide at low concentrations strongly enhances the inhibitory effect of nitric oxide on platelets. Biochem. J. 310:149-153.

28. Beckman, J.S., J. Chen, H. Ischiropoulos, and J.P. Crow. 1994. Methods Enzymol. 233:229-237.

29. Weyrich, A.S., X.L. Ma, D.J. Lefer, K.H. Albertine, and A.M. Lefer. 1993. In vivo neutralization of P-selectin protects feline heart and endothelium in myocardial ischemia and reperfusion injury. J. Clin. Invest. 91:2620-2629.

30. Davenpeck, K.L., T.W. Gauthier, and A.M. Lefer. 1994. Inhibition of endothelial-derived nitric oxide promotes P-selectin expression and actions in the rat microcirculation. Gastroenterology. 107:1050-1058.

31. Borders, J.L., and H.J. Granger. 1984. An optical doppler intravital velocimeter. Microvasc. Res. 27:117-125.

32. Granger, D.N., J.N. Benoit, M. Suzuki, and M.B. Grisham. 1989. Leukocyte adherence to venular endothelium during ischemia-reperfusion. Am. J. Physiol. 257:G683-G695.

33. Beckstead, J.H., P.E. Stenberg, R.P. McEver, M.C. Shuman, and D.F. Bainton. 1986. Immunohistochemical localization of membrane and granule proteins in human megakaryocytes: application to plastic embedded bone marrow biopsy specimens. Blood. 67:285-294.

34. Mullane, K.M., R. Kramer, and B. Smith. 1985. Myeloperoxidase activity as a quantitative assessment of neutrophil infiltration into ischemic myocardium. J. Pharmacol. Methods. 4:157-167.

35. Lefer, D.J., S.M.L. Shandelya, C.V. Serrano, L.C. Becker, P. Kuppusamy, and J.L. Zweier. 1993. Cardioprotective actions of a monoclonal antibody against CD-18 in myocardial ischemic-reperfusion injury. Circulation. 88 1779-1787.

36. Brunelli, L., J.P. Crow, and J.S. Beckman. 1995. The comparative toxicity of nitric oxide and peroxynitrite to Escherichia coli. Arch. Biochem. Biophys. 316:327-334.

37. Radi, R., J.S. Beckman, K.M. Bush, and B.A. Freeman. 1991. Peroxynitrite-induced membrane lipid peroxidation: the cytotoxic potential of superoxide and nitric oxide. Arch. Biochem. Biophys. 288:481-487.

38. Nguyen, T., D. Brunson, C.L. Crespi, B.W. Penman, J.S. Wishnok, and S.R. Tannenbaum. 1992. DNA damage and mutation in human cells exposed to nitric oxide in vitro. Proc. Natl. Acad. Sci. USA. 89:3030-3034.

39. Lin, K.-T., J.-Y. Xue, M. Nomen, B. Spur, and P.Y.-K. Wong. 1995. Peroxynitrite-induced apoptosis in HL-60 Cells. J. Biol. Chem. 270:16487-16490.

40. Villa, L.M., E. Salas, V.M. Darley-Usmar, M.W. Radomski, and S. Moncada. 1994. Peroxynitirite induces both vasodilation and impaired vascular relaxation in the isolated perfused rat heart. Proc. Natl. Acad. Sci. USA. 91: 12383-12387.

41. Moro, M.A. V.M Darley-Usmar, D.A Goodwin, N.G. Read, R. Zamora-Pino, M. Feelisch, M.W. Radomski, and S. Moncada. 1994. Paradoxical fate and biological action of peroxynitrite on human platelets. Proc. Natl. Acad. Sci. USA. 91:6702-6706.

42. Weyrich, A.S., X.-L. Ma, M. Buerke, T. Murohara, V.E. Armstead, A.M. Lefer, J.M. Nicolas, A.P. Thomas, D.J. Lefer, and J. Vinten-Johansen. 1994. Physiological concentrations on nitric oxide do not elicit an acute negative inotropic effect in unstimulated cardiac muscle. Circ. Res. 75:692-700

43. Miles, A.M., D.S. Bohle, P.A. Glassbrennor, B. Hansert, D.A. Wink, and M.B. Grisham. 1996. Modulation of superoxide-dependent oxidation and hydroxylation reactions by nitric oxide. J. Biol. Chem. 271:40-47.

44. Szabo, C., B. Zingarelli, and A.L. Salzman. 1996. Role of poly-ADP ribosyltransferase activation in the vascular contractile and energetic failure elicited by exogenous nitric oxide and peroxynitrite. Circ. Res. 78:1051-1063.

45. Mayer, B., A. Schrammel, P. Klatt, D. Koesling, and K. Schmidt. 1995. Peroxynitrite-induced accumulation of cyclic GMP in endothelial cells and stimulation of purified soluble guanylyl cyclase: dependence on glutathione and possible role of S-nitrosation. J. Biol. Chem. 270:17355-17360.

46. Moro, M.A., V.M. Darley-Usmar, I. Lizasoain, Y. Su, R.G. Knowles, M.W. Radomski, and S. Moncada. 1995. The formation of nitric oxide donors from peroxynitrite. Br. J. Pharmacol. 116:1999-2004.

47. Johnson, G., III, P.S. Tsao, and A.M. Lefer. 1991. Cardioprotective effects of authentic nitric oxide in myocardial ischemia with reperfusion. Crit. Care Med. 19:244-252.

48. Nakanishi, K., J. Vinten-Johansen, D.J. Lefer, Z. Zhao, W.C. Fowler, D.S. McGee, and W.E. Johnston. 1992. Intracoronary L-arginine during reperfusion improves endothelial function and reduces infarct size. Am. J. Physiol. 263:H1650-H1658.

49. Weyrich, A.S., X.-L. Ma, and A.M. Lefer. 1992. The role of L-arginine in ameliorating reperfusion injury after myocardial ischemia in the cat. Circulation. 86:279-288.

50. DeCaterina, R., P. Libby, H.-B. Peng, V.J. Thannickol, T.B. Rajavashisth, M.A. Gimbrone, Jr., W.S. Shin, and J.K. Liao. 1995. Nitric oxide decrease cytokine-induced endothelial activation. NO selectively reduces endothelial expression of adhesion molecules and proinflammatory cytokines. J. Clin. Invest. 96:60-68.

51. Kubes, P., M. Jutila, and D. Payne. 1995. Therapeutic potential of inhibiting leukocyte rolling in ischemia-reperfusion. J. Clin. Invest. 95:2510-2519. 